\title{
Erratum to: An advanced segmentation using area and boundary tracing technique in extraction of lungs region
}

\author{
Kiran THAPALIYA ${ }^{1}$, Sang-Woong LEE ${ }^{2}$, Jae-Young PYU ${ }^{1}$, Heon JEONG ${ }^{3}$, Goo-Rak KWON ${ }^{1}$
}

1. Department of Information and Communication Engineering, Chosun University, 375 Seosuk-Dong, Dong-Gn, Gwangju 501-759, Korea;

2. School of Computer Engineering, Chosun University, 375 Seosuk-Dong, Dong-Gu, Gwangju 501-759, Korea;

3. Deparment of Fire, Administration, Chodang University, Jellonamdo, Korea

(C) Central South University Press and Springer-Verlag Berlin Heidelberg 2014

Erratum to: J. Cent. South Univ. (2014) 21: 3811-3820

DOI: $10.1007 / \mathrm{s} 11771-014-2366-9$

The original version of this article unfortunately contained three mistakes. The mistakes are corrected as follows:

1) The spelling of third author is incorrect. The correct name is Jae-Young PYUN.

2) The information of corresponding author is incorrect. The correct information should be

Goo-Rak KWON, Professor, PhD; Tel/Fax: +98-711-7264102; E-mail: grkwon@chosun.ac.kr

3) The acknowledgement is incomplete. The updated acknowledgement is

This project is supported by Brain Research Program through the National Research Foundation of Korea funded by the Ministry of Science, ICT \& Future Planning (NRF-2013M3C7A1073001) and Ministry of Science, ICT and Future Planning (MSIP), Korea, under the IT/SW Creative Research Program supervised by the NIPA (National IT Industry Promotion Agency) (NIPA-2013-H0502-13-1094). 